\title{
Natural polyoxometalates: diversity, complexity and divergence from synthetic chemistry
}

\author{
Sergey V. Krivovichev ${ }^{1,2}$ \\ ${ }^{1}$ Kola Science Centre, Russian Academy of Sciences, Apatity, Russian Federation; \\ ${ }^{2}$ St. Petersburg State University, University Emb. 7/9, 199034 St. Petersburg, Russia; \\ skrivovi@mail.ru
}

Most research on polyoxometalates (POMs) has been devoted to synthetic compounds. However, recent mineralogical discoveries of POMs in mineral structures demonstrate their importance in geochemical systems. In total, fifteen different types of POM nanoscale size clusters in minerals have been found that occur in forty-three different mineral species. The topological diversity of POM clusters in minerals is rather restricted compared to the multitude of moieties reported for synthetic compounds, but the lists of synthetic and natural POMs do not overlap completely. The metal-oxo clusters in the crystal structures of the vanarsite-group minerals $\left(\left[\mathrm{As}^{3+} \mathrm{V}^{4+}{ }_{2} \mathrm{~V}^{5+}{ }_{10} \mathrm{As}^{5+}{ }_{6} \mathrm{O}_{51}\right]^{7-}\right)$, bouazzerite and whitecapsite $\left(\left[\mathrm{M}^{3+}{ }_{3} \mathrm{Fe}_{7}\left(\mathrm{AsO}_{4}\right)_{9} \mathrm{O}_{8-\mathrm{n}}(\mathrm{OH})_{\mathrm{n}}\right]\right)$, putnisite $\left(\left[\mathrm{Cr}^{3+}{ }_{8}\left(\mathrm{OH}_{16}\left(\mathrm{CO}_{3}\right)_{8}\right]^{8-}\right)\right.$, and ewingite $\left(\left[\left(\mathrm{UO}_{2}\right)_{24}\left(\mathrm{CO}_{3}\right)_{30} \mathrm{O}_{4}(\mathrm{OH})_{12}\left(\mathrm{H}_{2} \mathrm{O}\right)_{8}\right]^{32-}\right)$ contain metal-oxo clusters that have no close chemical or topological analogues in synthetic chemistry. The interesting feature of the POM cluster topologies in minerals is the presence of unusual coordination of metal atoms enforced by the topological restraints imposed upon the cluster geometry (the cubic coordination of $\mathrm{Fe}^{3+}$ and $\mathrm{Ti}^{4+}$ ions in arsmirandite and lehmannite, respectively, and the trigonal prismatic coordination of $\mathrm{Fe}^{3+}$ in bouazzerite and whitecapsite). Complexity analysis indicates that ewingite and morrisonite are the first and the second most structurally complex minerals known so far. The formation of nanoscale clusters can be viewed as one of the leading mechanisms of generating structural complexity in both minerals and synthetic inorganic crystalline compounds. The discovery of POM minerals is one of the specific landmarks of descriptive mineralogy and mineralogical crystallography of our time.

Keywords: polyoxometalates; minerals; structural complexity 